\title{
Test-Retest Reliability of Isometric Leg Muscle Strength Measurements Made Using a Hand-Held Dynamometer Restrained by a Belt: Comparisons during and between Sessions
}

MuNENORI KATOH, PT, $\mathrm{PhD}^{1)}$, HiROSHI YAMASAKI, PT, $\mathrm{PhD}^{2)}$

${ }^{1)}$ Department of Physical Therapy, Faculty of Health Science, Ryotokuji University: 5-8-1 Akemi, Urayasu-City, Chiba 279-8567, Japan.

${ }^{2)}$ Department of Physical Therapy, Kochi Rehabilitation Institute

\begin{abstract}
Purpose] The aim of this study was to evaluate the test-retest reliability of isometric muscle strength measurements made using a hand-held dynamometer restrained by a belt. [Subjects] The subjects were 37 healthy adults (18 men and 19 women) with a mean age of 21.9 years. [Methods] Measurements were made on the dominant leg using a hand-held dynamometer ( $\mu$ Tas MF-01 or F-1, Anima Corp., Tokyo) and a belt to fix the position of the body part under test. The strengths of the following 10 muscle groups were evaluated: flexors, extensors, abductors, adductors, internal rotators and external rotators of the hip; flexors and extensors of the knee; and dorsiflexors and plantar flexors of the ankle. Each measurement was repeated after at least 30 seconds of rest in three sessions: in the morning, in the afternoon on the same day, and one week later. [Results] The intraclass correlation coefficient (ICC) for the first and second sets of measurements made in each session ranged from 0.75 to 0.97 . ICC for the highest measurements of each muscle group in each of the three sessions ranged from 0.56 to 0.91 . [Conclusions] The test-retest reliability of isometric muscle strength measurements of the lower limb made using a hand-held dynamometer equipped with a stabilizing belt varies widely, depending on the muscle action tested, and it would be better to repeat the measurements on different occasions.
\end{abstract}

Key words: Muscle strength, Hand-held dynamometer, Test-retest reliability

(This article was submitted Jan. 15, 2009, and was accepted Apr. 6, 2009)

\section{INTRODUCTION}

Hand-held dynamometers are small devices that are relatively simple to use for quantitatively measuring muscle strength. However, the level of muscle strength that can be measured depends on the users because they must use their own strength to hold the sensor completely still against the forces applied by the examinee. This also makes interrater reliability poor $^{1-5)}$.

In a study by Wikholm et al. ${ }^{7)}$ in which muscle strengths of healthy subjects were evaluated by 3 raters, ICC was 0.226 for strength measurements of knee extensor muscles, which are strong, and 0.768 and 0.932 , respectively, for measurements of elbow flexor and shoulder external rotator muscles, which are weaker. In a study by Agre et al. ${ }^{8)}$ using 4 healthy subjects and 3 raters, Pearson correlation coefficients for interrater measurements ranged from -0.19 to 0.96 for the lower extremity, and from 0.88 to 0.94 for the upper extremity. Regarding the limitations of measurements using a 
Table 1. Subjects' posture, dynanometer position and belt fixation method during isometric muscle strength measurements made using a hand-held dynamometer with belt

\begin{tabular}{|c|c|c|c|c|}
\hline Exertion Task & Posture & Joint Position & Dynamometer Position* & Belt Fixation Method \\
\hline Hip flexion & Sitting upright(1) & $\begin{array}{l}\text { Hip flexed } 90^{\circ} \text {, popliteal } \\
\text { fossa floating }\end{array}$ & Femur head & Under table leg \\
\hline Hip extension & Prone (2) & Hip at $0^{\circ}$, distal femur floating & Femur head & Under table leg \\
\hline Hip abduction & Supine(3) & $\begin{array}{l}\text { Hip at } 0^{\circ} \text {, opposite pelvic side } \\
\text { on pillow,touching bed rail }\end{array}$ & Femur head & Around bed rail \\
\hline Hip adduction & Supine(4) & Hip at $0^{\circ}$, pelvis held by tester's hand & Femur head & Around tester's lower leg \\
\hline Hip external rotation & Sitting upright(1) & Hip at $0^{\circ}$, thigh horizontal & Medial maleolus & Around table leg \\
\hline Hip internal rotation & Sitting upright(1) & Hip at $0^{\circ}$, thigh horizontal & Lateral maleolus & Around table leg \\
\hline Knee flexion & Sitting upright(1) & Knee flexed $90^{\circ}$, thigh horizontal & Medial maleolus & Around tester's lower leg \\
\hline Knee extension & Sitting upright(1) & Knee flexed $90^{\circ}$, thigh horizontal & Medial maleolus & Around table leg \\
\hline Ankle plantar flexion & Prone(5) & Knee at $115^{\circ}$, ankle dorsiflexed $15^{\circ}$ & 1st metatarsal head & Around subject's thigh \\
\hline Ankle dorsiflexion & Sitting on chair (6) & $\begin{array}{l}\text { Heel on } 10 \mathrm{~cm} \text { block touching } \\
\text { bed rail, ankle dorsiflexed } 20^{\circ}\end{array}$ & 1st metatarsal head & Around bed rail \\
\hline
\end{tabular}

(1) On edge of a table (2) On table, more proximal than sensor (3) On bed (4) On mat (5) On table (6) Lower leg on bed * lower part of sensor placed on top of part of body under test in opposite direction to movement.

hand-held dynamometer(HHD), Hyde et al. ${ }^{10)}$ claimed that, regardless of the tester's experience or power of resistance, $30 \mathrm{~kg}$ is the limit, while Wiles et al. ${ }^{11)}$ and Roebeck et al. ${ }^{12)}$, claimed respectively that it is difficult to maintain the position of the HHD at forces of $300 \mathrm{~N}$ and $85 \mathrm{Nm}$ or higher.

We have tackled this problem by using a thin sensor and stabilizing it with a belt ${ }^{6}$. Using this technique, the interrater reliability of two testers, a man and a woman, was very good for various muscle strength measurements of the lower limb, with the intraclass correlation coefficient (ICC) ranging from 0.97 to 0.999 .

The aim of the present study was to assess the test-retest reliability of our methods. We compared measurements of lower limb muscle strength taken in the morning, and repeated in the afternoon and one week later.

\section{SUBJECTS AND METHODS}

The subjects were 37 healthy adults (18 men and 19 women) with a mean age of 21.9 (SD 1.5) years, and mean body weight of 57.6 (SD 6.7) $\mathrm{kg}$. They all had a right dominant leg, as determined by kicking a ball. None of the subjects had any joint pain or other orthopedic problems of the joints used in this study. All the subjects gave their informed consent to participate.

The HHD was a $\mu$ Tas MF-01 or F-1(Anima Corp., Tokyo). Its metal sensor was covered by a rubber pad. When the belt was used to secure the device, the sensor's Velcro fastener was used to secure the sensor to the part of the body under investigation, but when the belt was not used to secure the device, the sensor's Velcro fastener was used as a grip for the tester to hold when applying resistance. The belt length could be adjusted using a sliding bar buckle and a plate was used to fix the position of the sensor. The HHD had a measuring range from 0.0 to $80.0 \mathrm{kgf}$ with a precision of 0.1 kgf.

The strengths of each of the following 10 isometric muscle actions were evaluated during three sessions, in the morning, in the afternoon of the same day and one week later: flexion, extension, abduction, adduction, internal rotation and external rotation of the hip, flexion and extension of the knee, and dorsiflexion and plantar flexion of the ankle. The HHD was fixed to the subjects using the sensor's Velcro fastener. The HHD was equipped with a belt that could be secured to something immovable such as a bed leg (Table 1). The subjects ramped up to maximum the force of the 10 muscle actions over $3 \mathrm{~s}$, and then maintained a static state for about 5 seconds during which the peak force was noted. The exertions were repeated after a rest of at least 30 seconds. Measurements were made by a total of 5 male testers, each responsible for two muscle groups as indicted in Table 2. Before starting the actual measurements, the testers practiced using the same type of HHD to make the same type of measurements until familiar with the technique. 
Table 2. Characteritics of the testers who took isometric muscle strength measurements using a hand-held dynamometer fixed in position by a belt

\begin{tabular}{lccccc}
\hline Muscle action & Tester & Sex & Age & Height(cm) & Weight(kg) \\
\hline Hip flexion & A & M & 22 & 174.0 & 75.0 \\
Hip extension & A & M & 22 & 174.0 & 75.0 \\
Hip abduction & B & M & 26 & 175.0 & 70.0 \\
Hip adduction & B & M & 26 & 175.0 & 70.0 \\
Hip external rotation & C & M & 23 & 172.0 & 72.0 \\
Hip internal rotation & C & M & 23 & 172.0 & 72.0 \\
Knee flexion & D & M & 23 & 172.0 & 68.0 \\
Knee extension & E & M & 22 & 183.0 & 70.0 \\
Ankle plantar flexion & D & M & 23 & 172.0 & 68.0 \\
Ankle dorsiflexion & E & M & 22 & 183.0 & 70.0 \\
\hline
\end{tabular}

The statistical analyses were performed using SPSS for Windows (version 10.0, SPSS Japan Inc., Tokyo). Test-retest reliability was evaluated by ICC $(1,1)$ for data from the first and second sets of measurements in each session, the average measurements from each session, and the highest measurements from each session. When ICC was less than 0.9, the Spearman-Brown formula was used to calculate the number of measurements required to arrive at the standard coefficient of 0.9 .

\section{RESULTS}

The measurements and statistical analytical results for each muscle action are shown in Tables 3-5. The largest and smallest of the averages of each of the 3 pairs of measurements, one pair per session, were: hip flexion 23.1 and $26.3 \mathrm{kgf}$, hip extension 33.4 and $35.3 \mathrm{kgf}$, hip abduction 28.7 and $33.1 \mathrm{kgf}$, hip adduction 20.3 and $26.2 \mathrm{kgf}$, hip external rotation 15.0 and $16.3 \mathrm{kgf}$, hip internal rotation 19.1 and $21.8 \mathrm{kgf}$; knee flexion 20.5 and $22.9 \mathrm{kgf}$, knee extension 46.1 and $50.2 \mathrm{kgf}$; and ankle plantar flexion 66.3 and $73.4 \mathrm{kgf}$, and ankle dorsiflexion 16.3 and $17.1 \mathrm{~kg}$ (Table 3). ICC for the first and second sets of measurements in each session ranged from 0.75 to 0.97 . In cases where ICC was less than 0.9 , the number of required sets of measurements to reach 0.9 as predicted by the Spearman-Brown formula was 2-4 (Table 4). ICC for average and peak measurements of each session ranged from 0.56 to 0.92 and 0.56 to 0.91 , respectively. In cases where ICC was less than 0.9 , the number of required sets of measurements to reach 0.9 as predicted by the Spearman-Brown formula was 2-8 (Table 5).

\section{DISCUSSION}

Bohannon et al. ${ }^{7)}$ assessed the test-retest reliability of an isokinetic dynamometer (Cybex II) in the evaluation of 20 healthy women with a mean age of 29.2 years for the isometric muscle strength of unilateral knee flexion repeated after 30 seconds of rest in a single session, and reported an ICC of 0.932. In the present study, in which measurements of muscle action strengths were also repeated after 30 seconds of rest, the 30 calculated ICCs ranged from $0.75-0.95$, of which $21(70 \%)$ were 0.9 or higher. This suggests that the reliability of our measurements is about as high as those made using an isokinetic dynamometer. In the cases of the 9 ICCs below 0.9, from the Spearman-Brown formula, the required number of measurements necessary to reach a coefficient of 0.9 was 4 for knee flexions in the afternoon, 3 for knee flexions in the morning, and 2 for the other muscle actions. This suggests that 2 measurements will likely produce good reliability.

In previous studies, even when limited to healthy subjects, test-retest reliability of measurements repeated in different sessions were found to be poor, with widely scattered ICC values. Emery et al. ${ }^{8)}$ used an isokinetic dynamometer (Cybex Norm) to measure the strength of hip adduction and flexion at 60 degrees/second on both the dominant side (determined by preferred leg to kick a ball) and the non-dominant side of 19 healthy men aged 21-43 years. They repeated the measurements within 1 week and found that ICC ranged from 0.37 to 0.85 for the dominant leg and from 0.04 to 0.84 for the other leg. Kea et al. $\left.{ }^{9}\right)$ used an isokinetic dynamometer (Kin-Com) to measure the strength of hip adduction and abduction at 60 degrees/second (concentric and eccentric contraction) on the dominant side (also determined by preferred leg to kick a ball) of 27 male athletes with an average age of 20.2 years. They repeated the measurements 72 hours to 1 week later and found that ICC ranged from 0.59 to 0.74 . Lund et al. ${ }^{10)}$ used an isokinetic dynamometer (BIODEX) to measure the strength of extension and flexion of the knee and elbow of 13 healthy men and women with an average age of 32 years. They repeated the measurements after intervals of $20 \mathrm{~h}$ and 1 week and reported that ICC ranged from 0.96 to 0.98 for the $3^{\text {rd }}$ and $4^{\text {th }}$ measurements taken 20 minutes apart and ranged from 0.89 to 0.97 for measurements taken 1 week 
Table 3. Isometric muscle strength measurements of young healthy adults made using a hand-held dynamometer fixed in position by a belt $(n=37)$

\begin{tabular}{|c|c|c|c|c|c|c|}
\hline & & Hip flexion & Hip extension & Hip abduction & Hip adduction & Hip external rotation \\
\hline \multirow[t]{2}{*}{ Morning } & $1 \mathrm{st}$ & $23.1 \pm 7.1$ & $34.4 \pm 10.1$ & $30.2 \pm 8.5$ & $20.3 \pm 6.3$ & $15.9 \pm 4.7$ \\
\hline & 2nd & $24.6 \pm 7.4$ & $33.6 \pm 9.6$ & $29.5 \pm 8.3$ & $20.3 \pm 6.1$ & $15.0 \pm 4.3$ \\
\hline \multirow[t]{2}{*}{ Afternoon } & $1 \mathrm{st}$ & $25.8 \pm 6.5$ & $34.3 \pm 9.4$ & $33.1 \pm 8.8$ & $26.2 \pm 6.9$ & $16.1 \pm 4.9$ \\
\hline & 2nd & $26.3 \pm 6.5$ & $33.4 \pm 9.1$ & $33.0 \pm 8.2$ & $25.8 \pm 6.3$ & $15.5 \pm 4.5$ \\
\hline \multirow[t]{3}{*}{1 week later } & $1 \mathrm{st}$ & $26.0 \pm 6.5$ & $35.3 \pm 9.0$ & $29.2 \pm 6.7$ & $22.8 \pm 6.2$ & $16.3 \pm 5.1$ \\
\hline & 2nd & $25.3 \pm 5.7$ & $34.6 \pm 8.8$ & $28.7 \pm 6.6$ & $22.9 \pm 6.1$ & $16.0 \pm 4.8$ \\
\hline & & Hip internal rotation & Knee flexion & Knee extension & Ankle plantar flexion & Ankle dorsiflexion \\
\hline \multirow[t]{2}{*}{ Morning } & $1 \mathrm{st}$ & $20.4 \pm 5.8$ & $20.5 \pm 5.6$ & $46.1 \pm 15.0$ & $66.3 \pm 19.0$ & $16.4 \pm 4.1$ \\
\hline & 2nd & $20.2 \pm 5.6$ & $21.7 \pm 5.1$ & $46.7 \pm 14.5$ & $66.4 \pm 19.9$ & $16.3 \pm 4.4$ \\
\hline \multirow[t]{2}{*}{ Afternoon } & $1 \mathrm{st}$ & $21.8 \pm 4.7$ & $22.7 \pm 5.7$ & $50.2 \pm 16.8$ & $73.4 \pm 22.2$ & $17.0 \pm 4.4$ \\
\hline & 2nd & $21.5 \pm 4.7$ & $22.9 \pm 6.2$ & $50.1 \pm 16.9$ & $72.2 \pm 23.5$ & $16.8 \pm 4.2$ \\
\hline \multirow[t]{2}{*}{1 week later } & $1 \mathrm{st}$ & $20.1 \pm 5.1$ & $21.0 \pm 4.2$ & $46.7 \pm 14.9$ & $71.8 \pm 19.8$ & $17.1 \pm 3.5$ \\
\hline & 2nd & $19.1 \pm 4.7$ & $20.9 \pm 4.6$ & $46.2 \pm 14.0$ & $69.0 \pm 22.0$ & $16.7 \pm 3.3$ \\
\hline
\end{tabular}

Table 4. Test-retest reliability within each session for isometric muscle strength measurements of healthy young adults made using a hand-held dynamometer fixed in position by a belt

\begin{tabular}{|c|c|c|c|c|}
\hline Muscle action & Session & $\operatorname{ICC}(1,1)$ & $95 \% \mathrm{CI}$ & $k^{*}$ \\
\hline \multirow[t]{3}{*}{ Hip flexion } & Morning & 0.78 & $(0.62-0.88)$ & 3 \\
\hline & Afternoon & 0.89 & $(0.80-0.94)$ & 2 \\
\hline & 1 week later & 0.84 & $(0.71-0.91)$ & 2 \\
\hline \multirow[t]{3}{*}{ Hip extension } & Morning & 0.93 & $(0.86-0.96)$ & - \\
\hline & Afternoon & 0.96 & $(0.92-0.98)$ & - \\
\hline & 1 week later & 0.92 & $(0.85-0.96)$ & - \\
\hline \multirow[t]{3}{*}{ Hip abduction } & Morning & 0.95 & $(0.91-0.98)$ & - \\
\hline & Afternoon & 0.94 & $(0.88-0.97)$ & - \\
\hline & 1 week later & 0.93 & $(0.87-0.97)$ & - \\
\hline \multirow[t]{3}{*}{ Hip adduction } & Morning & 0.95 & $(0.90-0.97)$ & - \\
\hline & Afternoon & 0.95 & $(0.91-0.98)$ & - \\
\hline & 1 week later & 0.91 & $(0.84-0.95)$ & - \\
\hline \multirow[t]{3}{*}{ Hip external rotation } & Morning & 0.89 & $(0.80-0.94)$ & 2 \\
\hline & Afternoon & 0.94 & $(0.90-0.97)$ & - \\
\hline & 1 week later & 0.96 & $(0.93-0.98)$ & - \\
\hline \multirow{3}{*}{ Hip internal rotation } & Morning & 0.93 & $(0.87-0.97)$ & - \\
\hline & Afternoon & 0.83 & $(0.70-0.91)$ & 2 \\
\hline & 1 week later & 0.85 & $(0.74-0.92)$ & 2 \\
\hline \multirow[t]{3}{*}{ Knee flexion } & Morning & 0.73 & $(0.54-0.85)$ & 4 \\
\hline & Afternoon & 0.85 & $(0.73-0.92)$ & 2 \\
\hline & 1 week later & 0.90 & $(0.81-0.95)$ & 2 \\
\hline \multirow[t]{3}{*}{ Knee extension } & Morning & 0.94 & $(0.89-0.97)$ & - \\
\hline & Afternoon & 0.96 & $(0.92-0.98)$ & - \\
\hline & 1 week later & 0.96 & $(0.92-0.98)$ & - \\
\hline \multirow{3}{*}{ Ankle plantar flexion } & Morning & 0.90 & $(0.81-0.95)$ & - \\
\hline & Afternoon & 0.95 & $(0.91-0.98)$ & - \\
\hline & 1 week later & 0.93 & $(0.86-0.96)$ & - \\
\hline \multirow[t]{3}{*}{ Ankle dorsiflexion } & Morning & 0.96 & $(0.93-0.98)$ & - \\
\hline & Afternoon & 0.96 & $(0.93-0.98)$ & - \\
\hline & 1 week later & 0.93 & $(0.87-0.96)$ & - \\
\hline
\end{tabular}

ICC: intraclass correlation coefficient. $95 \%$ CI: $95 \%$ confidence interval. *Number of measurements required to obtain a coefficient of 0.9 as predicted by the Spearman-Brown formula.
Table 5. Test-retest reliability of isometric muscle strength measurements of healthy young adults made using a hand-held dynamometer fixed in position by a belt during 3 sessions

\begin{tabular}{|c|c|c|c|c|}
\hline Muscle action & Value & $\operatorname{ICC}(1,1)$ & $95 \% \mathrm{CI}$ & $k^{*}$ \\
\hline \multirow[t]{2}{*}{ Hip flexion } & Large $^{1)}$ & 0.75 & $(0.62-0.85)$ & 3 \\
\hline & Mean 2) & 0.75 & $(0.61-0.85)$ & 4 \\
\hline \multirow[t]{2}{*}{ Hip extension } & Large & 0.89 & $(0.82-0.94)$ & 2 \\
\hline & Mean & 0.89 & $(0.82-0.94)$ & 2 \\
\hline \multirow[t]{2}{*}{ Hip abduction } & Large & 0.80 & $(0.68-0.88)$ & 3 \\
\hline & Mean & 0.78 & $(0.65-0.88)$ & 3 \\
\hline \multirow[t]{2}{*}{ Hip adduction } & Large & 0.62 & $(0.44-0.76)$ & 6 \\
\hline & Mean & 0.60 & $(0.42-0.75)$ & 7 \\
\hline \multirow[t]{2}{*}{ Hip external rotation } & Large & 0.86 & $(0.77-0.92)$ & 2 \\
\hline & Mean & 0.88 & $(0.80-0.93)$ & 2 \\
\hline \multirow{2}{*}{ Hip internal rotation } & Large & 0.54 & $(0.36-0.71)$ & 8 \\
\hline & Mean & 0.54 & $(0.35-0.71)$ & 8 \\
\hline \multirow{2}{*}{ Knee flexion } & Large & 0.76 & $(0.63-0.86)$ & 3 \\
\hline & Mean & 0.77 & $(0.64-0.86)$ & 3 \\
\hline \multirow[t]{2}{*}{ Knee extension } & Large & 0.89 & $(0.82-0.94)$ & 2 \\
\hline & Mean & 0.91 & $(0.84-0.95)$ & - \\
\hline \multirow[t]{2}{*}{ Ankle plantar flexion } & Large & 0.81 & $(0.70-0.89)$ & 3 \\
\hline & Mean & 0.82 & $(0.72-0.90)$ & 2 \\
\hline \multirow[t]{2}{*}{ Ankle dorsiflexion } & Large & 0.76 & $(0.63-0.86)$ & 3 \\
\hline & Mean & 0.71 & $(0.57-0.83)$ & 4 \\
\hline
\end{tabular}

ICC: intraclass correlation coefficient.

95\% CI: 95\% confidence interval.

* Number of measurements required to obtain a coefficient of 0.9 as predicted by the Spearman-Brown formula.

${ }^{1)}$ Highest value of second trial in session.

${ }^{2)}$ Mean value of the two measurements sessions. 
apart. Möller et al. ${ }^{11)}$ used an isokinetic dynamometer (Kin-Com) for bilateral measurements of dorsiflexion and plantar flexion (concentric and eccentric contraction) of the ankle at 30 and 180 degrees/second in 10 healthy men with an average age of 37 years, and repeated the measurements 7 days later. ICC ranged from 0.34 to 0.96 when the subjects were in a sitting position, and from 0.00 to 0.85 when they were in a supine position. In the present study, ICC also varied widely, ranging from 0.56 to 0.91 when the highest measurements in each session were used. When ICC was less then 0.9, as calculated using the Spearman-Brown formula, the number of measurements required to obtain a coefficient of 0.9 for the highest measurements within sessions was 6 for adduction of the hip and 8 for internal rotation of the hip, and 2 or 3 for the other muscle actions. Therefore, for most muscle actions, 3 measurements may give high test-retest reliability, but for adduction and internal rotation of the hip, measurements should probably be made in more sessions.

\section{REFERENCES}

1) Hyde SA, Goddard CM, Scott OM: The myometer: the development of a clinical tool. Physiotherapy, 1983, 69: 424-427.

2) Wiles CM, Karni Y: The measurement of muscle strength in patients with peripheral neuromuscular disorders. J Neurol Neurosurg Psychiatry, 1983, 46: 1006-1013.

3) Roebroeck ME, Harlaar J, Lankhorst GJ: Reliability assessment of isometric knee extension measurements with a computer-assisted hand-held dynamometer.
Arch Phys Med Rehabil, 1998, 79: 442-448.

4) Wikholm JB, Bohannon RW: Hand-held dynamometer measurements: tester strength makes a difference. J Orthop Sports Phys Ther, 1991, 13: 191198.

5) Agre JC, Magness JL, Hull SZ, et al.: Strength testing with a portable dynamometer: reliability for upper and lower extremities. Arch Phys Med Rehabil, 1987, 68: 454-458.

6) Katou M, Yamasaki H: Comparison of reliability of isometric leg muscle strength measurements made using a hand-held dynamometer with and without a restraining belt. J Phys Ther Sci, 2009, 21: 37-42.

7) Bohannon RW: Hand-held compared with isokinetic dynamometry for measurement of static knee extension torque (parallel reliability of dynamometers). Clin Phys Physiol Meas, 1990, 11: 217-222.

8) Emery CA, Maitland ME, Meeuwisse WH: Test-retest reliability of isokinetic hip adductor and flexor muscle strength. Clin J Sport Med, 1999, 9: 79-85.

9) Kea J, Kramer J, Forwell L, et al.: Hip abductionadduction strength and one-leg hop tests: test-retest reliability and relationship to function in elite ice hockey players. J Orthop Sports Phys Ther, 2001, 31 : 446-455.

10) Lund $H$, S申ndergaard $K$, Zachariassen $T$, et al: Learning effect of isokinetic measurements in healthy subjects, and reliability and comparability of Biodex and Lido dynamometers. Clin Physiol Funct Imaging, 2005, 25: 75-82.

11) Möller M, Lind K, Styf J, et al.: The reliability of isokinetic testing of the ankle joint and a heel-raise test for endurance. Knee Surg Sports Traumatol Arthrosc, 2005, 13: 60-71.

12) Roebroeck ME, Harlaar J, et al.: Reliability assessment of isometric knee extention measuremants with a computer-assisted hand-held dynamometer. Arch Phys Med Rehabil, 1998, 79: 442-448 